\title{
REPORTS
}

\author{
RACHEL McKEE
}

Victoria University of Wellington

JACQUELINE ISELI

Independent Scholar

\section{Sign language interpreting in the Pacific: A snapshot of progress in raising the participation of deaf people}

\section{ABSTRACT}

Barriers to acquiring and using a shared sign language alienate deaf children and adults from their fundamental human rights to communication, education, social and economic participation, and access to services. International data collected by the World Federation of the Deaf (WFD) identify that in economically developing countries, deaf individuals are at particularly high risk of marginalization, which applies to countries in the Pacific region. This report provides a snapshot of the status of deaf people as sign language users in six Pacific nations: Fiji, Papua New Guinea (PNG), Samoa, Solomon Islands, Timor Leste and Kiribati. Information was contributed by

\section{KEYWORDS}

sign language deaf people deaf associations Pacific Islands human rights language access 
sign language interpreters from these countries during a panel convened at the first Oceania regional conference of the World Association of Sign Language Interpreters, in Fiji, 2018. The report outlines conditions for education through sign language and the emergence of sign language interpreting as a means of increasing access and social equity for deaf people in these countries, albeit this remains largely on a voluntary basis. While Fiji and PNG governments have recognized the status of sign languages in their respective countries and allocated some resources to the inclusion of sign language users, practical support of deaf sign language users tends to be progressed on grounds of disability rights rather than language rights; e.g., several Pacific countries have ratified the United Nations Convention on the Rights for People with Disabilities, which includes provisions for sign language users, and deaf advocacy efforts have gained political traction from alliance with disability organizations.

Amidst the diversity of languages in the Pacific, individuals who are deaf from birth or childhood are often marginalized from the aural-oral language milieu of their family and community. Communication and attitudinal barriers may limit their opportunities to participate in society. Yet, the risk of linguistic and social exclusion of deaf people is not unique to this region: a World Federation of the Deaf (WFD) survey of the human rights status of deaf people worldwide describes,

a huge lack of schools for Deaf children, very high illiteracy and unemployment rates, and great scarcity of sign language interpreters. The lack of statistics about Deaf people makes planning for and reasonable dimensioning of services targeted at Deaf people very difficult. Based on general observation, Deaf people are severely underserved in most countries.

(Haualand and Allen 2009: 14)

The WFD report states that $80 \%$ (or 47 million) of the world's deaf population live in developing countries, where deafness is more prevalent due to disease, accidents and environmental factors. WFD survey data received from 93 countries (no Pacific nations responded) show that 17\% of deaf children attend school, and only 3\% have access to education in the medium of sign language. In many countries, deaf people are precluded from civil rights such as obtaining a driver's licence or marrying; in 2009, most countries still lacked government supported interpreting services that enable sign language users to access public services, information and other domains of life, and especially so in developing countries (Haualand and Allen 2009). Reinforcing WFD's international advocacy for human rights for deaf sign language users, the Convention on the Rights of People with Disabilities (CRPD) (United Nations 2006) articulates that sign language is fundamental to the human rights of deaf people, as a medium of education, information, expression and accessible participation in society. State signatories to the CRPD thus have responsibilities to develop sign language interpreter training and interpreter services for deaf citizens. While some Pacific nations have demonstrated commitment to progressing human rights by ratifying the CRPD, there are significant challenges to developing the necessary resources and infrastructure to implement the goals specific to deaf people, especially where they are spatially dispersed, and/or hidden, within linguistically disparate communities.

The sociolinguistic situation of deaf people in Pacific nations is little documented. However, a Fiji Association of the Deaf statement applies more widely 
to the region: 'Currently, many Deaf people in Fiji and Samoa do not have access to any form of formal education or access to justice and fair treatment in all areas of our lives such as the workplace, community and public services' (Fiji Association of the Deaf n.d.). It is also known that restricted capacity to communicate with others and a 'disabled' status greatly heightens vulnerability to abuse (Anderson et al. 2011), especially in contexts where rates of sexual violence against women are high, such as PNG (Human Rights Watch 2015) and Vanuatu (Royson 2014; Iseli 2018).

The report published here sketches the situation for deaf sign language users in Fiji, PNG, Samoa, Solomon Islands and, more briefly, Timor Leste and Kiribati. These countries are selected because they were represented at the first Oceania regional conference of the World Association of Sign Language Interpreters in Fiji in August 2018, which provided an opportunity to record information from country representatives in a panel discussion. ${ }^{1}$ Their accounts are supplemented by other sources as available, and first-hand observations by authors Angela Murray and Jacqueline Iseli from their fieldwork as interpreters/educators in the Solomon Islands, Vanuatu and PNG. Our aim in this report is to inform language and translation scholars in the region of the linguistic and social marginalization experienced by deaf citizens and to highlight the importance of allies in supporting deaf-led advocacy for recognition of sign languages and interpreting services. For many of the 2018 WASLI Oceania conference participants, this event was their first opportunity to meet and observe others who work as sign language interpreters, and to compare experiences regionally.

Sign language interpreting as a formalized language service usually grows out of the voluntary practice of family members, teachers and social workers who navigate communication between deaf people and unfamiliar interlocutors, such as in medical, legal or public service encounters. In economically developed countries, this informal 'helper' model has evolved over time, through advocacy, into a professionalized service that insititutions engage to provide access to public services (Napier et al. 2010). However, a precursor to this progression is the consolidation of an adult deaf community who identify as users of a common sign language. The development of a nationally shared sign language is usually linked to a history of deaf education. Congregated schooling of deaf children expedites sign language development in two ways: (1) by bringing dispersed children together, which enables spontaneous development of a shared language among themselves and across generational cohorts, and/or (2) by introducing a foreign sign language via nationals of a colonizing country or an NGO. Both aspects of this process are playing out in Pacific nations at varying stages. Government recognition of the need for interpreting often follows from the formation and advocacy of a national Deaf Association. For many Pacific countries, these conditions are still emergent, and the language status of deaf people individually and collectively may remain unrecognized and under-supported.

In observing that the adoption and localization of foreign sign languages via school and church-led initiatives in the Pacific have brought deaf people together in new ways, we do not mean to obviate the fact that deaf people in remote locations, and without schooling, often have their own local or individual ways of communicating through signs and other visual modes, often shared mainly with non-deaf interlocutors (Branson and Miller 2004; Branson and Miller 2011; Reed et al. 2018). Nevertheless, such diverse sign language
1. Panel contributors were Gael Seru, Fiji; Roselyn Willie, PNG; Marie Enosa, Samoa; Nester Piko, Solomon Islands; Eufragia De M. Soares, Timor Leste; and Tuane Neemia, Kiribati. 
2. Discussion of the impacts of colonial dissemination of sign languages/systems in global south countries is beyond the scope of this brief report, but see for example, Branson and Miller 2004, 2011; Fenlon and Wilkinson 2015; Moriarty Harrelson 2017; Okombo and Akach 1997.

3. Australasian Signed English is one of many pedagogically devised sign systems that adapts sign vocabulary from a natural deaf sign language (in this case Auslan), with the addition of contrived signs to represent English words and particles on the hands. Such systems aim to manually 'code' spoken language, and are usually articulated by teachers simultaneously with speaking. Signed systems are very different in their structure and visual comprehensibility to the natural sign languages of deaf communities, which do not code the elements of a spoken language, but recruit the visual properties of space, motion, iconicity and embodiment in their grammars. Sign systems seem to be better understood by those who have prior command of the spoken language, which is not the case for children who are deaf from birth or infancy. repertoires lead to practical and ideological complexity for organizations aiming to empower deaf people through the development of formal education and interpreting services.

\section{FIJI}

Among the Pacific island nations, deaf education and interpreting in Fiji are the most developed, and neighbouring countries look to Fiji's experience to support their development. School and church missions for deaf people were established in Suva from the 1970s by individuals from New Zealand, Australia and Nigeria, who each brought various forms of sign language from their own countries to their interaction with local deaf people, who did not, at the time, apparently share a common form of signing to serve as a medium of formal education. ${ }^{2}$ From church and school sites of deaf interaction, Fiji Sign Language (FJSL) has evolved with a lexicon drawn originally from Australasian Signed English (a system used in deaf education in Australia and New Zealand in the 1980s), ${ }^{3}$ mixed with American signs introduced by deaf educators from Nigeria (which was previously missionized by American deaf educators), and local Fiji signs (see Nelson et al. 2009).

FJSL is currently used mainly in Suva and a few other large centres; elsewhere, opportunities for learning and socialization in the medium of sign language are limited, and deaf children in some rural areas may experience little access to language and education. Considerable variation in sign language use exists across regions and individuals, depending on their life circumstances. The Ministry of Education has adopted an inclusive education policy, which favours enrolment of children with disabilities in regular schools. While there are some deaf teachers who teach pre-school and primary age deaf children in the medium of FJSL, this is limited to a few special schools: about seventeen special schools exist around Fiji and only one (in Suva) caters specifically for deaf students. Some of the students enter school at a very late age, without prior schooling or language (The Gospel School for Deaf n.d.). An 'inclusive' policy for deaf children is problematic to implement without early opportunities for children to acquire and interact with others in sign language and the availability of trained communication support staff, as also seen in other Pacific countries (and elsewhere) that have adopted this policy.

The Fiji Association of the Deaf (FAD) was founded in 2002, and its leadership has built alliances with partners around Fiji, Pacific and Oceania. Their mission is,

[t]o provide people who are Deaf with equal opportunities so that they can live as equal members in the wider society. To help people who are Deaf to gain an independence and the ability to advocate for their own needs.

(Fiji Association of the Deaf n.d.)

From school and church sites of deaf interaction in Suva in the 1990s, a need for interpreting emerged - to access church services, high-school education and later on, courts, police and parliament - although training and reimbursement for interpreting were not available then (Nelson et al. 2009). An intensive training course in 2006 was a collaboration between local interpreters and New Zealand and Australian interpreter educators (Nelson et al. 2009). This training advanced practice knowledge, generated awareness of interpreter roles in the deaf community and encouraged the formation of a Fiji Sign Language 
Interpreters Association. The FAD and Interpreters Association identify a need for a permanent training programme to consolidate interpreting as a profession and to expand interpreter numbers. Currently, FAD lists approximately 60 individuals with interpreting skills across Fiji, with about twenty engaged in full-time employment (mostly in schools), while five work freelance in community settings. Interpreters booked by FAD for community-based assignments such as police interview, hospital visit, family meeting - are normally paid, with government funding. FAD negotiates payment with different organizations, for example the Judicial department provides hourly and daily rates, plus transport, which are implemented mainly in Suva and most recently in Lautoka. The Disability Resource Centre directly engages or contracts some interpreters. In schools, interpreter pay and recognition have improved over time, but conditions are demanding: interpreters work alone, without breaks between class spells, and are expected to perform additional tasks such as tutoring or committee service. Interpreters report that while many deaf students are doing well in school with interpreting support, greater workforce capacity and professional development for interpreters is urgently needed. At the university level, some interpreters are contracted to work with deaf students attending on Australian DFAT (Department of Foreign Affairs and Trade) scholarships, and FAD hopes to see a fee waiver for interpreters in exchange for service to encourage interpreters to gain higher qualifications.

Fiji passed a law protecting the rights of people with disabilities in 2016, and ratified the United Nations CRPD in June 2017. Since 2014, the Fiji government has implemented its Constitutional principle (section 25), that every person has the right to information, by televising FJSL interpretation of parliamentary sessions, with hearing and deaf interpreters working collaboratively on this linguistically challenging task. Yet, more fundamental access gaps persist, for example in 2017 a member of FAD highlighted barriers to justice and services as a deaf woman, saying, ' $\mathrm{i}] \mathrm{t}$ is really hard for deaf persons to communicate on social issues such as domestic violence. Deaf women living with violence do not know where to go and how to seek assistance. It is difficult to communicate without sign language' (UNDP 2017). Meanwhile, employment opportunities for interpreters have progressed somewhat, but FAD notes that general employment opportunities and pay for deaf individuals, even those with training and qualifications, remain inequitable.

\section{PAPUA NEW GUINEA}

Indigenous localized sign languages in PNG have been described in Enga (Kendon 1980), Oro and Chimbu provinces (Ethnologue), and the Western Highlands (Reed et al. 2018) as being used by deaf individuals and familiar networks of non-deaf people within these areas. However, as in Fiji, Australasian Signed English was introduced in the 1990s when deaf education provision was established (mainly in the Port Moresby area), bringing a strong influence on local signing. Mixed with some local signs, this was initially re-named 'Melanesian Sign Language' (Tamarua and Stebbins 1994). In 2015, 'Papua New Guinea Sign Language' (PNGSL) was legally recognized as an official language by the government, although the meaning of this is not entirely clear; for example, television reportage about PNGSL recognition shows teachers and deaf school students using Australasian Signed English (EMTV 2015), and local informants report that, '[b]ooks purported to be of PNGSL up to this point were actually of Auslan' (Wikipedia n.d.). In practice, teachers observe that deaf children come from diverse family language 
backgrounds, and many bring a repertoire of home signs created with relatives; attempts to teach through an English-based sign system were found to be ineffective for students and teachers, for example, in the East New Britain Deaf Unit, which comprised twelve deaf students 5-24 years of age. Teachers have recently recognized the value of working with deaf teaching assistants who can communicate more richly in local forms of sign language based on visual-spatial grammar and semantics that are more comprehensible to deaf children. A senior educator explains:

We were teaching them word by word English and that's where we have made a mistake. We just realized that, and the deaf themselves are telling us. We are learning now from them that sign language belongs to them and we have to do it the way they feel is correct.

(Willie 2018)

Currently, a Deaf Project Leader is leading a group, including the Summer Institute of Linguistics (SIL), to develop a PNGSL dictionary that reflects local variants; however, it is not clear to what extent the scope will include varieties of signing that may exist outside urban and school contexts (Reed et al. 2018).

Interpreting as a distinct practice and role is just emerging, mainly in Port Moresby. To date, interpreting for deaf adults in community contexts and children in schools has been done ad hoc by teachers of the deaf, using a Signed English approach, with teacher and interpreter roles merged - practices that are now understood to limit communication access. Training workshops for interpreters have been delivered by deaf and hearing trainers from Fiji and Australia since 2006, while interpreting continues to be provided on a volunteer basis. Exceptions are that the National Broadcasting Commission employs interpreters to present the TV news in PNGSL, and a major NGO, Callan Services, is looking to fund community interpreting. Two Deaf Associations and a Sign Language Interpreters' Association have been formed, and are advocating for sign language interpreter training and provision, whilst discussions are in progress with a university about the possibility of establishing a sign language interpreter training programme. Funding, interpreter training expertise and linguistic disparity among deaf people are challenges.

\section{SAMOA}

Samoa is more linguistically homogenous than PNG or Fiji, but like other Pacific nations, entrenched attitudes and a largely non-urban population challenge the provision of deaf education in sign language or interpreting services for adults. Consequently, a small proportion of deaf people have opportunities to acquire and use a shared 'Samoan' sign language, which is a localized form of Australasian Signed English, as in PNG and Fiji. Deaf Australian volunteers have also likely increased contact with Auslan. An inclusive education policy is in place, although there are few personnel skilled to work with deaf children who attend local schools. Some teachers who work for SENESE, an organization that implements support for inclusive education, also serve as interpreters, and they cover a large (itinerant) caseload and broad job description. One special school for students with various disabilities includes a group of deaf students, but there is no deaf-specific education facility in Samoa where younger deaf children can develop language practices together, and staff can develop expertise in deaf 
pedagogy. Through collaboration with the FAD, a Samoan Deaf Association has been established, which provides a representative voice and a point of connection with regional and international deaf organizations. In 2018, a Sign Language Interpreters Association was founded with 30 members; of these, five actively work as interpreters, within other employment roles or on a voluntary basis. Australian and Fiji interpreters have led intermittent professional development opportunities, and this small group of highly motivated interpreters are keen for further training and development as a profession.

\section{SOLOMON ISLANDS}

In the Solomon Islands, members of a language group are referred to as 'wantok' ('one talk'), and it is this identity that deaf people now aspire to develop as an emerging community of sign language users, with a growing sense of mutual identity that challenges their ascribed status as 'deaf and dumb'. Prior to 2008, deaf people scattered throughout the islands had little opportunity to meet other deaf people or to receive an education, and thus a common sign language was shared only among a small network who attended a mixed disability primary school in Honiara, the nation's capital. Another recent centre of education and interaction is the San Isidro Care Centre, a vocational training centre for deaf adults in a village called Aruligo, about a 40-minute drive from Honiara. This was established for young deaf adults from all over the Solomon Islands and approximately one-third of students who attend have had no education prior to their arrival at the San Isidro Care Centre and, for many, it is their first contact with other deaf people and their first experience of communicating in a conventional sign language. The San Isidro Care Centre is a registered Rural Training Centre, which provides instruction in applied skills (agriculture, carpentry, building, life-skills and basic literacy and maths) to equip students to contribute to developing their home community. Teaching staff have included deaf people, but no teachers have had training to educate deaf people, and there are still a few staff members who cannot sign.

Solomon Islands Sign Language is developing, drawing on various sources, with much individual variation, given the diverse circumstances in which deaf individuals innovate or adopt signs. First documentation of the recently named 'Solomon Islands Sign Language' occurred in a 2009 project at the San Isidro Care Centre, involving the students who wanted to document their signs for other deaf people and families of deaf children (Murray 2009). Australasian and Fijian signs are the basis; however, it is distinctive by the use of locally coined signs and vocabulary and grammatical influences from Solomon Islands Pidgin. Interpreting as a distinct practice is just emerging, and is currently undertaken by a few committed individuals who have come from teaching roles (a common circumstance through the Pacific). A project sponsored by the New Zealand Sign Language Interpreters Association, and the World Association of Sign Language Interpreters in 2010, supported workshops for deaf people and aspiring interpreters, led by a deaf teacher and an interpreter from Fiji. The Fiji interpreter (Joneti Rokotuibau) observed:

The training was an empowerment to the Solomon Islands Deaf students. Serevi (the deaf teacher) spoke on several topics. Deaf culture was an eye opener for them, seeing a role model who is Deaf like them, 
and a qualified Deaf teacher [...] the boys were so excited to see his stories and ask him many questions. We showed them pictures of our Deaf members in Fiji doing activities and playing sport like them, and Solomon Islanders would only ask one question: 'Are they Deaf?'.

(Murray and Rokotuibau 2011)

The project demonstrated the value of collaboration and role modelling between neighbouring countries that share some cultural context and a history of addressing similar challenges for deaf people.

\section{TIMOR LESTE}

An important development in 2004 was the founding of a small deaf school ('Agape') in Dili by a teacher from the Phillipines, which now receives government support. The language of instruction is American Sign Language, but the school hopes that 'a native, standardised sign language - Timorese Sign Language - will take root and evolve in its own, unique way' (Agape School for the Deaf n.d.). Under former Indonesian occupation, a'standardized'Indonesian sign system was used at the school (Joshua Project n.d.), although during this period deaf students were co-enrolled with children with other physical disabilities and sign language instruction was not well implemented. Operation of the school ceased during civil unrest in 2006, but the Agape school now enrols 50 deaf students 6 to 52 years of age, teaching academic, vocational and sporting skills. The school models empowerment by training senior deaf students as teachers, four of whom have been employed since 2011. In May 2012, six athletes from the school competed in the Asia-Pacific Deaf Games in Seoul, and again in 2015 in Taiyuan. Timor Leste has recently formalized a Deaf Association and a Deaf Sports Federation. A small number of individuals work as interpreters on a volunteer basis, except when working for a private organization or an NGO agency that pays for certain interpreting assignments. Government funding for sign language interpreting is not available as yet.

\section{KIRIBATI}

An Australian Volunteers for International Development (AVID) project in 2016 contributed to establishing a Deaf Association by bringing deaf people together to work on a first dictionary, comprising 'images of signs with Kiribati and English translations' (Anon. 2016). FJSL/Auslan vocabulary is reportedly the basis, as many local deaf people who use sign language attended school in Fiji, which has created development links between these countries. Interpreters have benefited from a training workshop delivered by Fiji interpreters and are working to raise government awareness of the need for sign language accessibility, for example, by voluntarily interpreting at public events where they are visible to officials. Recently, the Kiribati Institute of Technology, with Australian DFAT aid, partnered with the Deaf Association to offer construction classes for deaf students, and sign language training for staff and the public, as part of an initiative to support meaningful employment pathways for i-Kiribati with disabilities (Nossal Institute for Global Health, University of Melbourne 2018).

\section{CONCLUSION}

Within and across Pacific countries, formal associations and informal networks of deaf and hearing people are working together to address multi-faceted barriers to language, education and social inclusion for deaf people. Each 
country is at a different stage of changing societal attitudes towards deaf people's capacity, developing and disseminating a common sign language, and establishing interpreting arrangements. Many aspects of this trajectory mirror the experience of deaf communities and interpreters worldwide (e.g., countering pejorative beliefs about sign language, and urban-rural disparity in access to education and interpreting), while some challenges are regionally specific (e.g., the dispersed location of deaf individuals across many islands and their diverse language affilliations). Governments in Fiji and PNG have taken important steps by recognizing a sign language in their respective countries and allocating institutional support and resources to their use. Associations of Deaf people and of sign language interpreters in Fiji are providing leadership to other countries in the region, whilst still building their own capacity and international deaf-world alliances. Deaf development in the Pacific is focused on expanding educational opportunities for deaf children and adults in the medium of sign language, and strengthening the capacity of national Deaf Associations to advance the goals of deaf people.

Interpreters, whether voluntary or paid, trained or untrained, share an awareness that they are critical partners in empowering the voice of deaf leaders to self-advocate, and in facilitating new opportunities for deaf individuals to participate in educational and community contexts. In their everyday work, Pacific interpreters are tasked to work across extremely diverse language repertoires of deaf people, often in situations of complex disadvantage in which there are no other appropriate sources of support to call upon. Priorities for interpreters in this region include training and mentoring, defining locally relevant standards of practice and raising institutional awareness of interpreting as a skilled (preferably remunerated) service.

These goals require continued strategic cooperation with local allies (such as education and disability stakeholders), applied language researchers, aid NGOs and government enitities, and collaboration with peers in other Pacific countries. Membership of international organizations that promote these same goals worldwide - namely, the WFD and the World Association of Sign Language Interpreters - offers solidarity and lends weight to local advocacy. Development leaders in this region should also be cognisant of the experiences of deaf communities in other global south countries, in which well-intentioned language interventions in sociolinguistically complex situations have had unintended outcomes on language and identity politics among deaf communities (Branson and Miller 2004; Kusters et al. 2015; Moriarty Harrelson 2017).

\section{REFERENCES}

Agape School for the Deaf (n.d.), http://agapeschoolforthedeaf.com/about-us/ who-we-are/. Accessed 24 May 2019.

Anderson, Melissa L., Leigh, Irene W. and Samar, Vincent J. (2011), 'Intimate partner violence against Deaf women: A review', Aggression and Violent Behavior, 16:3, pp. 200-06.

Anon. (2016), 'First sign language dictionary in Kiribati', AVID, 19 September, https://dfat.gov.au/people-to-people/volunteers/avid-news-events/newsletters/avid-0916/Pages/first-sign-language-dictionary-in-kiribati.aspx. Accessed 4 April 2019.

Branson, Jan and Miller, Don (2004), 'The cultural construction of linguistic incompetence through schooling: Deaf education and the transformation of the linguistic environment in Bali, Indonesia', Sign Language Studies, 5:1, pp. 6-38. 
(2011), 'National sign languages and language policies', in Stephen May (ed.), Encyclopedia of Language and Education, Boston, MA: Springer, pp. 89-98.

EMTV (2015), 'Sign language to be introduced as fourth official language', EMTV, 7 May, https://www.youtube.com/watch?v=Ttq-RP5s-oA. Accessed 24 May 2019.

Fenlon, Jordan and Wilkinson, Erin (2015), 'Sign languages in the world', in Adam C. Schembri, and Ceil Lucas (eds), Sociolinguistics and Deaf Communities, Cambridge: Cambridge University Press, pp. 5-28.

Fiji Association of the Deaf (n.d.), 'About the project', Fiji Association of the Deaf, https://millneckinternational.org/our-work/fiji/. Accessed 4 April 2019.

The Gospel School for Deaf (n.d.), http://www.fijideaf.net/school.html. Accessed 4 April 2019.

Haualand, Hilde and Allen, Colin (2009), Deaf People and Human Rights, World Federation of the Deaf and the Swedish National Association of the Deaf, https://www.rasit.org/files/Deaf-People-and-Human-Rights-Report.pdf. Accessed 5 April 2019.

Human Rights Watch (2015), Bashed Up: Family Violence in Papua New Guinea, New York: Human Rights Watch.

Iseli, Jacqueline (2018), Deaf Ni-Vanuatu and their Signs: A Sociolinguistic Study, MA thesis, Victoria University of Wellington.

Joshua Project (n.d.), 'Deaf in East Timor', https://joshuaproject.net/people_ groups/19007/TT. Accessed 4 April 2019.

Kendon, Adam (1980), 'A description of a deaf-mute sign language from the Enga Province of Papua New Guinea with some comparative discussion Part I: The formational properties of Enga signs', Semiotica, 31:1\&2, pp. 1-34.

Kusters, Annelies, Toura-Jensen, Outi, Verhelst, Filip and Vestergaard, Ole (2015), 'Changing the world (or not): Reflecting on interactions with the Global South during the Frontrunners program', in Michele Friedner and Annelies Kusters (eds), It's a Small World: International Deaf Spaces and Encounters, Washington, DC: Gallaudet University Press, pp. 249-61.

Moriarty Harrelson, Erin (2017), 'Deaf people with"no language": Mobility and flexible accumulation in languaging practices of deaf people in Cambodia', Applied Linguistics Review, 10:1, pp. 55-72.

Murray, Angela (2009), A Booklet for Learning Basic Solomon Islands Sign Language, Aruligo: Regional Assistance Mission to the Solomon Islands.

Murray, Angela and Rokotuibau, Joneti (2011), 'Working together to support the Solomon Islands: An emerging Deaf and interpreting community', in Brendan Costello, Mary Thumann and Risa Shaw (eds), Proceedings of the 4th Conference of the World Association of Sign Language Interpreters, Durban, South Africa, 14-16 July.

Napier, Jemima, McKee, Rachel and Goswell, Della (2010), Sign Language Interpreting, Sydney: The Federation Press.

Nelson, Karen, Tawaketini, Inise, Ruth, Spencer and Goswell, Della (2009), 'Isa Lei: Interpreter training in Fiji', in Jemina Napier (ed.), International Perspectives on Sign Language Interpreter Education, Washington, DC: Gallaudet University Press, pp. 171-89.

Nossal Institute for Global Health, University of Melbourne (2018), 'Skills for employment for i-Kiribati with disability', https://mspgh.unimelb. edu.au/centres-institutes/nossal-institute-for-global-health/news-and- 
events/skills-for-employment-for-i-kiribati-with-disability. Accessed 4 April 2019.

Okombo, D. O. and Akach, P. O. (1997), 'Language convergence and wave phenomena in the growth of a national sign language in Kenya', International Journal of the Sociology of Language, 125:1, pp. 131-44.

Reed, Lauren, Rumsey, Alan, Merlan, Francesca and Onga, John (2018), 'The communicative ecology of deaf sign languages in the Western Highlands of Papua New Guinea', Seminar for Centre of Excellence for the Dynamics of Language, Australian National University, Canberra, 12 October, https:// cloudstor.aarnet.edu.au/plus/s/2ShUz8KKfmK8YaM/download. Accessed 8 April 2019.

Royson, Willie (2014), 'Be Alarmed! Vanuatu rates of violence against women and children', Vanuatu Daily Post, 2 October, http://dailypost.vu/news/ be-alarmed-vanuatu-rates-of-violence-against-women-and-children/ article_fbf9a7fb-4f4c-58f4-a305-cfc8058accec.html. Accessed 23 May 2019.

Tamarua, Jennifer and Stebbins, Keith (1994), Melanesian Signs for Communication with the Deaf, Port Moresby: Department of Education, Papua New Guinea.

United Nations (2006), 'Convention on the rights of persons with disabilities - articles', https://www.un.org/development/desa/disabilities/ convention-on-the-rights-of-persons-with-disabilities/convention-onthe-rights-of-persons-with-disabilities-2.html. Accessed 4 April 2019.

UNDP (2017), 'Sign language on board for equal access to services and advocating for the rights', 16 November, UNDP Pacific Office, Fiji, http://www. pacific.undp.org/content/pacific/en/home/presscenter/articles/2017/11/16/ sign-language-on-board-for-equal-access-to-services-and-advocatingfor-the-rights.html. Accessed 30 March 2019.

Wikipedia (n.d.), 'Papua New Guinean sign language',Wikipedia, https:// en.wikipedia.org/wiki/Papua_New_Guinean_Sign_Language - cite_noteISO-1. Accessed 24 May 2019.

Willie, Rosely (2018), in person interview with Angela Murray, Fiji, 18 August.

\section{SUGGESTED CITATION}

McKee, Rachel, Iseli, Jacqueline and Murray, Angela (2019), 'Sign language interpreting in the Pacific: A snapshot of progress in raising the participation of deaf people', Journal of New Zealand \& Pacific Studies, 7:2, pp. 185-96, doi: https://doi.org/10.1386/nzps_00005_1

\section{CONTRIBUTOR DETAILS}

Dr Rachel McKee is associate professor and programme director of NZSL Studies in the School of Linguistics and Applied Language Studies, Victoria University of Wellington. She has worked in the sign language interpreting field as a practitioner, trainer and researcher since 1985, and published widely in applied sign linguistics, mainly on New Zealand Sign Language.

Contact: NZSL Studies, School of Linguistics and Applied Language Studies, Victoria University of Wellington, PO Box 600, New Zealand.

E-mail: rachel.mckee@vuw.ac.nz

Angela Murray is a qualified NZSL interpreter. She is currently the Oceania regional representative for the World Association of Sign Language Interpreters. 
She spent a year volunteering in the emerging interpreter and deaf community in the Solomon Islands, and has built connections with colleagues in the Pacific region to support development in this field. During fieldwork, Angela led the first documentation of Solomon Islands Sign Language.

E-mail: angemurray@gmail.com

Jacqueline Iseli is a qualified NZSL interpreter and in 2018 she completed an MA thesis at Victoria Univesity of Wellington that documented the sociolinguistic situation of deaf people in Vanuatu. This followed three years of Volunteer Service Abroad in Vanuatu and PNG. She produced a first dictionary of signs used by deaf individuals in Vanuatu and promoted the development of sign language awareness for teachers working with deaf children.

Contact: Blind Foundation, Te Tūāpapa o Te Hunga Kāpō, Private Bag 94002. Manukau 2240, Auckland, New Zealand.

E-mail: jacquiiseli@maxnet.co.nz

Jacqueline Iseli, Rachel McKee and Angela Murray have asserted their rights under the Copyright, Designs and Patents Act, 1988, to be identified as the authors of this work in the format that was submitted to Intellect Ltd. 